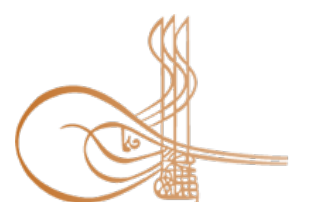

www.turkishstudies.net/economy
Turkish Studies - Economics, Finance, Politics

eISSN: $2667-5625$

Research Article / Araștırma Makalesi

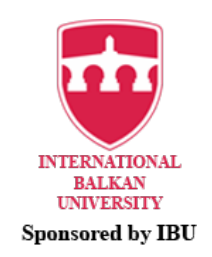

Sponsored by IBU

\title{
GARCH Modeli ve DVM - EKK Regresyonu ile Kripto Para Fiyat Öngörüsü: Bitcoin Fiyatı Üzerine Bir Uygulama
}

\author{
Cryptocurrency Price Forecasting with GARCH Model and LS - SVM Regression: An Application \\ on Bitcoin Price
}

\author{
Hayri Abar
}

\begin{abstract}
The aim of this study is to determine whether successful predictions for cryptocurrencies such as Bitcoin can be obtained with different methods. The reason why Bitcoin prices (Bitcoin / \$) are used in the study is that this cryptocurrency is still the most widely used cryptocurrency in the market, and the idea that it will successfully represent the overall state of the cryptocurrencies market. Financial market series may contain fluctuations for some reason, such as speculations. It also usually includes nonlinear changes. Such features lead to failures in obtaining forecasts for financial time series. In this study, with the GARCH model, one of the classicial time series models and LS - SVM method, a machine learning method, predictions of the Bitcoin price series were obtained, and model performances were compared. In the study, between January 01, 2017 and February 29, 2020, 1155 daily Bitcoin price series $\left(P_{t}\right)$ was used. In both models, the Bitcoin price series and the volatilities of this series were used, and external variables were not included in the models. For both models, forecasts were obtained for periods of 1 month, 2 months and 3 months. For GARCH and LS - SVM models, out of sample successful forecasting rates according to MAPE ratios were 98,0347\% - 95,3423\% for 1 month; $97,9544 \%$ - 96,1307\% for 2 months and $98,1272 \%$ - 91,4874\% for 3 months, respectively. The GARCH model has provided more successful results for all three periods. The finding of the study is that the GARCH model can be used to obtain forecasts for the crypto price series.
\end{abstract}

Structured Abstract: The use of cryptocurrency as an investment and payment instrument has become widespread since it was developed by Nakamoto (2008). Especially recently, Bitcoin usage has been increasing. An important factor affecting this increase is undoubtedly the extraordinary increase in Bitcoin prices. Since these increases led to Bitcoin's significant returns, that made Bitcoin an important investment tool. However, Bitcoin prices contain significant uncertainties and volatility. These factors can also lead to great losses. Therefore, the forecast of Bitcoin prices is an important research topic.

Studies in the literature on cryptocurrencies focus on different purposes. The focus may be on future price or return, volatility, or relationships with other investment instruments. In studies aiming to forecast the future price, there are studies using cryptocurrency's lagged values as well as studies using different economic and financial indicators. In this study, the Bitcoin price series and the volatilities of this series were used, and external variables were not included in the models. When the literature is examined, it is noteworthy that there

* Dr. Öğr. Üyesi, Gaziantep Üniversitesi, İktisadi ve İdari Bilimler Fakültesi, İktisat Bölümü
Assistant Prof. Dr., Gaziantep University, Faculty of Economics and Administrative Sciences, Department of Economics
ORCiD 0000-0002-2043-6747
hayriabar@gmail.com
Cite as/ Atıf: Abar, H. (2020). GARCH modeli ve DVM - EKK regresyonu ile kripto para fiyat öngörüsü: Bitcoin
fiyatı üzerine bir uygulama. Turkish Studies - Economy, 15(2), 705-725. fiyatı üzerine bir uygulama. T
https://dx.doi.org/10.29228/TurkishStudies.42926

Received/Geliş: 16 April/Nisan 2020

Accepted/Kabul: 20 June/Haziran 2020

Copyright $($ INTAC LTD, Turkey

Checked by plagiarism software

Published/Yaym: 25 June/Haziran 2020

CC BY-NC 4.0 
are not many studies focusing on Bitcoin price forecasting. The aim of this study is to determine whether successful predictions for cryptocurrencies such as Bitcoin can be obtained with different methods. The reason why Bitcoin prices (Bitcoin / \$) are used in the study is that this cryptocurrency is still the most widely used cryptocurrency in the market, and the idea that it will successfully represent the overall state of the cryptocurrencies market. Financial market series may contain fluctuations for some reason, such as speculations. It also usually includes nonlinear changes. Such features lead to failures in obtaining forecasts for financial time series.

Since financial series are generally heteroscedastic, when the forecasts of these series are aimed to be obtained, the heteroscedasticity should also be taken into consideration. This problem can be overcome by using GARCH models. Machine learning and deep learning algorithms can also be used to obtain forecasts for these series. Support vector machines is a machine learning method that can be used to achieve forecasts. Support vector machines can be used for purposes that learning, classification, and clustering etc. It also provides successful results in modeling nonlinear series. The nonlinear regression model based on minimization of squared errors can be estimated using support vector machines. This method is called Least Squares - Support Vector Machines (LS - SVM) Regression. In this study, using the GARCH model, one of the classical time series models, and using LS - SVM method, a machine learning method, predictions of the Bitcoin price series were obtained, and model performances were compared using predictive performance evaluation criteria.

In the study, between January 01, 2017 and February 29, 2020, 1155 daily Bitcoin price series $\left(P_{t}\right)$ was used. The data used were obtained from the https://coinmarketcap.com web page. For both models, forecasts were obtained for periods of 1 month, 2 months and 3 months. In this study, comparing the in sample performances would be misleading as the aim of estimating the models is to obtain the forecasts of the future. For this purpose, comparisons were made according to out of sample performances. GARCH $(1,1)$ model was used in the study. For the LS - SVM model, a non-parametric volatility indicator is used in addition to the lags of the price series. This indicator increased the predictive performance of the model.

Since methods such as the GARCH model have many assumptions and do not contain specific rules for determining the model specifications, the use of these models can be complicated. Machine learning methods are more flexible in this regard. The findings obtained in most studies indicate that learning and machine learning algorithms provide more successful results. However, according to the findings obtained in this study, the GARCH model performs more successfully. Although the LS-SVM method provides very successful performance for in - sample, the GARCH model is more successful in terms of out of sample performance. LS - SVM method's in - sample success can be attributed to overfitting. For GARCH and LS SVM models, out of sample successful forecasting rates according to MAPE ratios were 98,0347\% - 95,3423\% for 1 month; 97,9544\% - 96,1307\% for 2 months and 98,1272\% - 91,4874\% for 3 months, respectively. The GARCH model has provided more successful results for all three periods. The finding of the study is that the GARCH model can be used to obtain forecasts for the crypto price series.

Keywords: Financial Time Series Analysis, Applied Statistics, Bitcoin, Forecasting, GARCH Model, LS SVM Regression

Öz: Bu çalışmada amaç Bitcoin gibi kripto paralar için başarılı öngörülerin farklı yöntemlerle elde edilip edilemeyeceğinin belirlenmesidir. Çalışmada Bitcoin fiyatlarının (Bitcoin/\$) kullanılma nedeni bu kripto para biriminin hala piyasada en yaygın kullanılan kripto para birimi olması ve kripto para birimleri piyasasının genel durumunu başarılı bir şekilde temsil edeceği düşüncesidir. Finansal piyasalara ait seriler spekülasyonlar gibi bazı nedenlerle dalgalanmalar içerebilmektedir. Ayrıca genellikle doğrusal olmayan değişimler içermektedir. $\mathrm{Bu}$ gibi özellikleri, finansal zaman serileri için öngörülerin elde edilmesinde başarısızlıklara yol açmaktadır. $\mathrm{Bu}$ çalışmanda klasik zaman serisi modellerinden GARCH modeli ve bir makine öğrenme yöntemi olan DVM - EKK yöntemiyle Bitcoin fiyat serisine ait kestirimler elde edilmiş, model performansları karşılaştırılmıştır. Çalışmada 01 Ocak 2017 - 29 Şubat 2020 dönemi, 1155 günlük Bitcoin fiyat serisi $\left(P_{t}\right)$ kullanılmıştır. Her iki modelde de Bitcoin fiyat serisi ve bu seriye ait oynaklıklar kullanılmış, dışsal değişkenler modellere dâhil edilmemiştir. Her iki modele göre de öngörüler 1 ay, 2 ay ve 3 aylık periyotlar için elde edilmiştir. GARCH ve DVM - EKK modelleri için MAPE oranlarına göre örneklem dışı başarılı öngörü oranları sırasıyla 1 ay için \%98,0347 - \%95,3423; 2 ay için \%97,9544 - \%96,1307 ve 3 ay için \%98,1272 - \%91,4874'dir. GARCH 
modeli her üç periyot için de daha başarılı sonuçlar elde edilmesini sağlamıştır. Çalışmanın bulgusu GARCH modelinin kripto para fiyat serisi için öngörülerin elde edilmesinde kullanılabileceği yönündedir.

Anahtar Kelimeler: Finansal Zaman Serileri Analizi, Uygulamalı İstatistik, Bitcoin, Öngörü, GARCH Modeli, DVM - EKK Regresyonu

\section{Giriș}

Kripto paranın bir yatırım ve ödeme aracı olarak kullanımı Nakamoto (2008) tarafindan geliştirildiğinden bu yana yaygınlaşmaktadır. Özellikle ABD'de vergi sonuçları olan yasal bir para birimi/araç olarak ilan edildiği 2013'ün sonlarından bu yana Bitcoin'in kullanımı katlanarak artmıștır (Troster vd., 2019: 187). Medyanın haberleri ve ilgisinin de etkisiyle Bitcoin fiyatları Ocak 2017'den Aralık 2017 ortasına kadar yaklaşık \%1700 oranında artmıştır (Bleher ve Dimpfl, 2019: 147). Bu dönemde Bitcoin ve diğer kripto paralar cazip bir yatırım aracına haline gelmiştir. Günümüzde kripto paraların toplam piyasa değeri yaklaşık olarak 190 milyar ABD dolarıdır (CoinMarketCap, 2020).

Bitcoin gibi kripto paralar, herhangi bir üçüncü kişi veya herhangi bir finansal kurumun müdahalesi olmayan özel bir değişim aracı olarak tasarlanmıştır (Rane ve Dhage, 2019: 594).Sentetik emtia olarak da tabir edilebilen kripto para merkezi olmamasının yanında hem emtianın hem de itibari paranın bazı özelliklerini taşımaktadır (Selgin, 2015: 93). Fakat kripto paralar için yapılan işlemler bankacılık sisteminde yer alan itibari para için finansal kuruluşlar tarafından getirilen işlem ücreti, kural, yönetmelik ve kısıtlamalara tabi değildir (Wołk, 2019: 1). Kripto paralar, bu gibi özellikleri nedeniyle yatırım ve değişim aracı olarak kullanılabilmektedir. Kıtlı̆̆ının sabit ve belirli olması nedeniyle teknolojideki değișim veya yeni kaynakların bulunmasından etkilenmemesi; parasal olmayan alternatif kullanımları olmaması nedeniyle talebinin değişken olması gibi bir nedenle satın alma gücünün değişmemesi; temininin politik veya değişken motivasyonlara bağlı olmaması gibi önemli avantajlara sahiptir (Selgin, 2015: 95).

Kripto paraların kullanımın artması yatırımcılar ve araştırmacıların dikkatini çekmiş ve bu alanda yapılan çalışmalar giderek önem kazanmıştır. Kripto para piyasası oldukça kompleks olmasına rağmen yükssek getiri ve diğer yatırım araçlarıyla düşük korelasyona sahip olması gibi avantajlara sahiptir (Sun vd., 2020: 1). Düşük korelasyon yatırım çeşitlendirmesi için önemli bir avantaj sağlamaktadır. Kripto paranın sahip olduğu yüksek oynaklık ve fiyat belirsizliği yatırımcıların zarar etmesine yol açabilmektedir (Munim vd., 2019: 1). Bu nedenle yatırım aracı olarak kullanacaklar ve politikacılar açısından kripto paraların gelecekteki değerinin belirlenmesi önem arz etmektedir. Çünkü sadece kripto para üzerine yatırım yapmayı planlayan bir yatırımcı dahi yaklaşık 2000 farklı alternatife sahiptir. Diğer yatırım araçlarıyla birlikte değerlendirildiğinde çeşitlilik oldukça artmaktadır. Fiyat öngörüsü, portföy optimizasyonu ve riskten kaçınma açısından önem arz etmesine rağmen özellikle Bitcoin için çok az çalışma bu konuya odaklanmıştır (Lahmiri ve Bekiros, 2019: 36).

Literatürde klasik zaman serisi modelleri, derin öğrenme ve makine öğrenmesi gibi alternatif yöntemler öngörü amacıyla yaygın şekilde kullanılmaktadır. Bu yöntemler verilerin doğrusal olmayan yapılarını dikkate alarak öngörüler elde edilmesini sağlamaktadır. Son yıllarda özellikle yüksek seviyeli doğrusal olmayan öngörülerin elde edilmesi probleminde yapay zekâ sistemlerinin kullanımı giderek artmaktadır (Lahmiri ve Bekiros, 2019: 39). Bu çalışmanda klasik zaman serisi modellerinden GARCH modeli ve bir makine öğrenme yöntemi olan DVM - EKK yöntemiyle Bitcoin fiyat serisine (Bitcoin/\$) ait kestirimler elde edilmiş, model performansları karşılaştırılmıştır. Çalışmada Bitcoin fiyatlarının kullanılma nedeni bu kripto para biriminin hala piyasada en yaygın kullanılan kripto para birimi olması ve kripto para birimleri piyasasının genel durumunu başarılı bir şekilde temsil edeceği düşüncesidir. 
Bu çalışmada öngörü modelinde altın fiyat1, döviz kuru, petrol fiyat1, borsa endeksi, Google aramaları vb. değiş̧kenler kullanmak yerine otoregresif modeller kullanılarak öngörü yapılmıştır. Çünkü bu gibi değişkenler Bitcoin getirilerinin öngörüsünün başarılı bir şekilde elde edilmesini sağlamamaktadır (Aalborg vd., 2019: 255). Çalışma literatür özeti, veriler ve yöntem, bulgular ve tartışma ile devam edecek ve sonuç ve öneriler kısmı ile sonlandırılacaktır.

\section{Literatür Özeti}

Kripto paralarla alakalı literatürdeki çalışmalar farklı amaçlara odaklanabilmektedir. Çalışmalarda odak noktası gelecekteki fiyat veya getiri (Lahmiri ve Bekiros, 2019; Munim vd., 2019; Sun vd., 2020; Troster vd., 2019), oynakl1k (Aalborg vd., 2019; Bleher ve Dimpfl, 2019; Hattori, 2020) veya diğer yatırım araçlarıyla ilişkiler (Balli vd., 2019; Güleç vd., 2018; Isah ve Raheem, 2019) olabilmektedir. Gelecekteki fiyatın öngörüsünü amaçlayan çalışmalarda kripto paranın geçmiş dönem değerlerini kullanan çalışmalar (Hattori, 2020; Lahmiri ve Bekiros, 2019; Munim vd., 2019) olduğu gibi farklı faktörler kullanan çalışmalar (Adcock ve Gradojevic, 2019; Li ve Wang, 2017; Sun vd., 2020; Walther vd., 2019) da bulunmaktadır.

Sun vd. (2020) çalışmalarında 42 çeşit kripto para birimi için üç farklı veri madenciliği yöntemini: DVM, RF ve LightGBM kullanarak çeşitli ekonomik göstergeler ile öngörü yapmışlardır. Çalışmada 01.01.2018 - 06.30.2018 dönemi günlük veriler kullanılmıştır. Ekonomik göstergeler olarak çeşitli ülkelere ait borsa endeksleri, Amerikan Doları Endeksi ve Ham Petrol WTI Vadeli İşlemleri Fiyatı kullanılmıştır. Öngörüler fiyatlar için değil fiyatların artacağını veya azalacağını belirleyecek şekilde yapılmıştır. Kullanılan yöntemler en iyi sonuçları orta vade (2 hafta) için vermektedir. Ayrıca daha yaygın kullanılan kripto paralar için daha başarılı öngörüler elde edilmiştir. LightGBM'nin, dirençlilik açısından DVM ve RF'ye göre daha iyi sonuç verdiği ve çok sayıda veri ve değişken için etkili bir yöntem olduğu çalışmanın önemli bulgularındandır.

Çılgın vd. (2020) çalışmalarında makine öğrenmesi yöntemleriyle Twitter verileri için metin sınıflandırması yapmışlar, elde edilen sınıflandırılmış verilerle Bitcoin fiyatı arasındaki korelasyonu hesaplamışlardır. Kullanılan veriler 06 Ekim 2018 - 19 Mayıs 2019 dönemine aittir. Çalışmada YSA, Lojistik Regresyon, Destek Vektör Makineleri ve Naive Bayes siniflandirma modelleri kullanılmıştır. Eğitim verisi üzerinden yapılan analizlerde en yüksek başarılı sınıflama oranı YSA ile elde edildiğinden sınıflandırılmamış metinlerin sınıflandırılmasında YSA kullanılmıştır. Sınıflanan metinler için olumlu tweet oranı hesaplanmış ve Bitcoin kapanış fiyatlarıyla korelasyonu elde edilmiştir. Olumlu tweet oranı ile Bitcoin fiyatı arasında orta üstü aynı yönlü ilişki tespit edilmiştir.

Hatori (2020) çalışmasında Bitcoin piyasası için temsili oynaklık göstergesi ve GARCH, GJR-GARCH, EGARCH, APARCH ve IGARCH modellerini kullanarak oynaklık modellemesi yapmıştır. Yazar tarafından Ocak 2016 - Temmuz 2018 dönemine ait 5 dakikalık frekans aralığında elde edilen veriler kullanılmıştır. Çalışmada oynaklık göstergesi olarak günlük getirinin kareleri ile hesaplanan "gerçekleştirilen oynaklık" kullanılmıştır. EGARCH ve APARCH asimetrik oynaklık modelleri daha başarılı kestirimlerin elde edilmesini sağlamıştır. Normal dağılımlı oynaklık modelleri çarpık - t gibi kalın kuyruklu dağılımlı modellere göre daha başarılı sonuçlar elde edilmesini sağlamıştır.

Evci (2020) çalışmasında Bitcoin fiyatlarında haftanın günleri açısından anomalilikleri tespit etmiştir. Çalışmada 28 Nisan 2013 - 22 Kasım 2019 dönemi günlük veriler kullanılmıştır. Anomalililer gölge değişkenler kullanılarak modellenmiştir. Çalışmada EGARCH modeli kullanılmış, Bitcoin getirilerinde anomalilikler olduğu tespit edilmiştir. Ortalama getiri pazartesi ve perşembe günleri pazar gününe göre daha azdır.

Kartal (2020) çalışmasında Bitcoin fiyatlarını bir veri madenciliği yöntemi olan K-Star algoritması ile modellemiştir. Çalışmada 3 Ocak 2017 - 30 Ocak 2019 dönemi günlük veriler kullanılmıştır. Çalışmada amaç fiyatın düşeceğinin veya yükseleceğinin öngörüsüdür. Çalışmada 
S\&P 500 Endeksi, Brent Ham Petrol Fiyat1 (USD), Avro/Dolar Paritesi, 1 Ounce USD değeri ve 10 Yıl Vadeli ABD Tahvil Faiz Oranları dışsal faktörler olarak kullanılmıştır. Kurulan modellin yükseliş ve düşüşleri başarılı bir şekilde öngörme oranı \%61,1'dir. Yazar modelin öngörü performansının başarılı sayılabilecek bir düzeyde olmakla birlikte beklenenin altında olduğunu belirtmiştir.

Mallqui ve Fernandes (2019) çalışmalarında Bitcoin fiyatının en yüksek ve en düşük değerlerini, yönünü ve kapanış fiyatını belirlemeyi amaçlamışlardır. Kullanılan veriler 19 Ağustos 2013 - 19 Temmuz 2016 dönemine aittir. Çalışmada SVM, ANN ve RNN ve K-Means kümeleme algoritması temelli kolektif algoritmalar kullanılmıştır. Çalışmada eğitim ve test verisi olarak 80 20 (aralık 1) ve 75 - 25 (aralık 2) oranları kullanılmıştır. Regresyon denemelerine göre kestirim için her iki aralık için en büyük, en küçük ve kapanış fiyatlarının öngörüsünde en başarılı sonuçlar SVM ile elde edilmiştir. Benzer şekilde kapanış fiyatlarının öngörüsünde de SVM en iyi sonuçların elde edilmesini sağlamıştır.

Munim vd. (2019) çalışmalarında ARIMA ve NNAR modellerini kullanarak Bitcoin fiyat öngörüsü yapmışlardır. Analizler 1 Ocak 2012 - 4 Ekim 2018 dönemini kapsayan günlük verilerle gerçekleştirilmiştir. Eğitim verisi için RMSE, MAPE ve MASE kriterlerine göre NNAR daha başarılı öngörüler elde edilmesini sağlasa da ARIMA modeli test verisi için daha başarılı öngörüler elde edilmesini sağlamıştır. Diebold Mariano (DM) testine göre de test verisi için ARIMA modelinin daha başarılı olduğu sonucuna ulaşılmıştır. Genel olarak ifade edilecek olursa; oynaklık içeren Bitcoin fiyat öngörüsünde ARIMA modelinin daha uygun olduğu ifade edilmiştir.

Aalborg vd. (2019) çalışmalarında Bitcoin'in getiri, oynaklık ve ticaret hacminin öngörüsünde hangi değişkenlerin kullanılması gerektiğini belirlemeyi amaçlamışlardır. Kullanılan değişkenler: işlem hacmi, benzersiz kullanıcı adresi sayısı, VIX endeksi ve Google aramaları sayısıdır. Çalışmada çok değişkenli regresyon modeli kullanılmıştır. Çalışmada 1 Mart 2012 - 19 Mart 2019 dönemi günlük ve haftalık veriler kullanılmıştır. Bitcoin getirilerinin kestiriminde modellerin yetersiz kaldığı; günlük oynaklık kestiriminde nispeten başarılı sonuçlar elde edilse de modellerin haftalık oynaklık kestirimi için yetersiz kaldığ 1 ve ticaret hacmi için sadece Google aramaları ve işlem hacminin başarılı kestirimlere olanak sağladığı tespit edilmiştir.

Lahmiri ve Bekiros (2019) çalışmalarında derin öğrenme yöntemleriyle en yaygın kullanımı olan üç kripto para birimi olan Bitcoin, Digital Cash ve Ripple için fiyat öngörüsü gerçekleştirmişlerdir. Öngörülerin elde edilmesinde LSTM ve GRNN yöntemleri kullanılmıştır. Analizler Bitcoin için 16 Temmuz 2010 - 01 Ekim 2018; Digital Cash için 8 Şubat 2010 - 1 Ekim 2018 ve Ripple için 21 Ocak 2015 - 1 Ekim 2018 dönemi günlük verilerle gerçekleştirilmiştir. Dijital para birimleri incelenen örnekleme süresine bağlı olarak kaotik özellikler sergilemektedir. Bu üç farklı dijital para birimi için de LSTM daha iyi öngörüler elde edilmesini sağlamış ayrıca kestirim dönemine göre test dönemi için fraktal desenlerin belirlenmesinde daha başarılı olmuştur. Genel olarak, derin öğrenmenin en çok işlem gören kripto para birimleri için doğal kaotik kalıpların öğrenilmesinde ve öngörülmesinde oldukça etkili olduğu tespit edilmiştir.

Troster vd. (2019) çalışmalarında GARCH ve GAS modellerini kullanarak Bitcoin için getiri ve risk öngörüsü yapmışlardır. Çalışmada 19 Haziran 2010 - 16 Nisan 2018 dönemi günlük fiyat verileri kullanılmıştır. Çalışmada logaritmik getiri ve riske maruz değer değişkenleri kullanılmıştır. Uyum iyiliği ve öngörü performansı açısından bulgular kalın kuyruk GAS modellerinin Bitcoin getiri ve riski için daha başarılı sonuçlar elde edilmesini sağladığını göstermektedir.

Bleher ve Dimpfl (2019) çalışmalarında Google ile arama yoğunluğunu kullanarak 12 farklı kripto para için oynaklık ve getiri öngörüsü yapmışlardır. Çalışmada 18 Eylül 2013 - 30 Eylül 2018 aralığında farklı kripto para birimleri için farklı dönem verileri kullanılmıştır. Analizler saatlik, günlük ve haftalık veriler kullanılarak yapılmıştır. Oynaklık değerleri parametrik olmayan bir varyans ölçünün karekökü alınarak elde edilmiştir. Öngörülerin elde edilmesinde VAR modeli kullanılmıştır. Saatlik öngörülerde en iyi sonuç otoregresif modelle elde edilmiştir. Arama yoğunluk 
indeksi günlük ve haftalık veriler için başarıyı artırmıştır. Genel olarak değerlendirilecek olursa Google arama yoğunluğu kripto paralar için oynaklık için başarılı kestirimlerinin elde edilmesini sağlamıştır fakat aynı durum getiri için geçerli değildir.

Wołk (2019) çalışmasında kripto para birimleri için sosyal medya duyarlılık analizleri yapmıştır. Çalışmada lineer regresyon ve Bayesian ridge regresyon modelleri yanında çeşitli makine öğrenme yöntemleri kullanılmıştır ve Google ve Twitter verileri kullanılmıştır. Kripto para dalgalanmaları sosyal medya ve Google aramalarına bağlıdır. Fakat yüksek oynaklık nedeniyle kripto para fiyat öngörüsü oldukça güçtür. Elde edilen bulgulara göre tüm modellerin ortalaması olan hibrit model en iyi sonuçların elde edilmesini sağlamıştır.

Adcock ve Gradojevic (2019) çalışmalarında Bitcoin getirileri için fiyat ve yoğunluk tahmini yapmışlardır. Çalışmada ARIMAX, GARCH-M, doğrusal regresyon, kantil regresyon ANN ve kernel regresyon kullanılmıştır. Çalışmada 19 Temmuz 2010 - 5 Mart 2018 dönemi verileri kullanılmıştır. Çalışmada 50 günlük alış - satış sinyali, 200 günlük alış - satış sinyali ve VIX oynaklık endeksi kullanılmıştır. Çalışmada tüm modellerin öngörü performansı rassal yürüyüş modelinkiyle karşılaştırılmıştır. Kullanılan modellerden sadece tekrarlayan yapay sinir ağları rassal yürüyüş modelinden daha iyi sonuç vermiştir. Benzer şekilde yoğunluk öngörüsü için de YSA modeli en uygun sonuçların elde edilmesini sağlamıştır.

Balli vd. (2019) çalışmalarında kısa, orta ve uzun vadede genelleştirilmiş öngörü hata varyans ayrışması ve dalgacık uyum analizi kullanarak kripto para birimlerinin dinamik bağlılığını araştırmışlardır. Çalışmada 5 Ağustos 2014 - 25 Temmuz 2018 dönemi verileri kullanılmıştır. Çalışmada Bitcoin, Ripple, Stellar, Litecoin, Monero ve Dash için analizler gerçekleştirilmiştir. Ayrıca VIX, OVX ve GVZ endeksleri kullanılarak kripto para birimlerinin finansal ve ekonomik belirsizlikten nasıl etkilendiği belirlenmeye çalışılmıştır. Elde edilen bulgulara göre, kripto para birimlerinin artan popülaritesiyle birlikte bağlılıkları da artmaktadır. Çeşitli belirsizlik kaynakları bu bağlantılılık üzerinde etkilidir. Kripto paralar arasındaki ilişkiler ekonomik belirsizlikten ters yönde etkilenmektedir.

Figá-Talamanca ve Patacca (2019) çalışmalarında piyasa ilgisi göstergelerinin Bitcoin getiri ve oynaklığg üzerindeki etkilerini araştırmışlardır. Çalışmada 1 Ocak 2012 - 31 Aralık 2017 dönemi günlük veriler kullanılmıştır. Çalışmada piyasa ilgisi göstergeleri olarak toplam Bitcoin işlem hacmi ve Google aramaları kullanılmıştır. Çalışmada öngörüler ARMA, GARCH ve EGARCH modelleriyle elde edilmiştir. Bitcoin getirilerinin oynaklığ 1 , işlem hacminden ve Google arama yoğunluğundan büyük ölçüde etkilenirken, ortalama getiri işlem hacminin seviyesinden etkilenmektedir. Ayrıca ilgi göstergelerinin kullanılması öngörü başarısını artırmıştır.

Pele ve Mazurencu-Marinescu-Pele (2019) çalışmalarında Bitcoin getirileri için riske maruz değer (VaR) öngörüsü yapmışlardır. Çalışmada 10 Ağustos 2015 - 10 Şubat 2018 dönemi günlük veriler kullanılmıştır. Çalışmada Bitcoin için hesaplanan entropi değişkeni ve lojistik regresyon, GARCH ve AR modelleri kullanılmıştır. Entropi, Bitcoin fiyat ve getirisini açıklamada önemli bir faktördür. Entropi katsayısı pozitif ve anlamlıdır. Bu durum Bitcoin'in fiyat dinamiklerinin piyasa belirsizliğinden kaynaklanabileceğine işaret etmektedir. Entropi günlük getirilerde uç değerlerin ortaya çıkma ihtimali ile aynı yönlü ilişkilidir. Entropi, Bitcoin fiyatlarının gelişimindeki kriz dönemleri için bir kestirim aracı olarak kullanabilir. VaR tahmini gün içi getirilerin entropisine dayanmaktadır ve bu model klasik GARCH modellerinden elde edilen öngörüler arasında en iyisidir.

Giudici ve Pagnottoni (2019) çalışmalarında Bitstamp, Gemini, Coinbase, Kraken ve Bittrex Bitcoin alım satım platforlarının birbirlerine bağımlılıklarını ekonometrik bağımlılık göstergeleriyle incelemişlerdir. Çalışmada 1 Temmuz 2017 - 30 Haziran 2018 dönemi saatlik veriler kullanılmıştır. Çalışmada VECM ve VAR modeli kullanılmıştır. Analizler toplam yayılma endeksi kullanılarak gerçekleştirilmiştir. Bağımlılık piyasaların yükseliş dönemin azalırken piyasaların düşüş döneminde artmaktadır. Bitfinex ve Gemini fiyat belirleme konusunda öncü platformken Bittrex takipçi 
konumundadır. Alım satım piyasaları arasında Bitcoin getirisi açısından yayılma etkisi bulunmaktadır ve bu etki zamana göre değişkenlik içermektedir.

Isah ve Raheem (2019) çalışmalarında Bitcoin'in ABD hisse senedi piyasaları üzerindeki kestirim performansını ve kestirim performansı üzerinde parasal genişleme politikasının etkisini araştırmışlardır. Parasal genişleme gölge değişken veya temsili değişkenler kullanılarak modele dâhil edilmiştir. Çalışmada regresyon modeli tahmini yapılmıştır. Çalışmada Temmuz 2010 - Temmuz 2018 dönemi haftalık veriler kullanılmıștır. Sadece Bitcoin fiyatının kullanıldığı model, parasal genişlemenin gölge değişkenler aracılığıyla dikkate alındığı modele göre daha başarılı performans sergilemiştir. Fakat parasal genişleme temsili değişkenlerle modele dâhil edildiğinde öngörü performansını artırmıştır. Genel olarak değerlendirilecek olursa Bitcoin fiyatları hisse senedi getirilerinin kestiriminde başarılı performans sergilemektedir.

Walther vd. (2019) çalışmalarında Bitcoin, Etherium, Litecoin, Ripple, Stellar ve kripto para indeksi (CRIX) için günlük, haftalık ve aylık oynaklık öngörüsü yapmışlardır. Çalışmada öngörü modellerinde 17 farklı dışsal finansal ve ekonomik gösterge kullanılmıştır. Günlük fiyatlar, başlangıç tarihi farklı para birimlerine göre değişmekle birlikte, 31 Temmuz 2019'a kadar verilerden oluşmaktadır. Çalışmada GARCH ve GARCH-MIDAS modelleri kullanılmıştır. Çalışmada en iyi öngörüler küresel reel ekonomik aktivite indeksinin dışsal olarak kullanıldığı modelle elde edilmiştir. En iyi ikinci öngörü ise tüm modellerin öngörü ortalamaları ile elde edilmiştir.

Demir vd. (2019) çalışmalarında Bitcoin için fiyat kestirimi yapmışlardır. Çalışmada 2010 2019 yılları arası günlük veriler kullanılmıştır. Kestirimler 12 dışsal faktör kullanılarak yapılmıştır. Çalışmada LSTM, DVM, YSA, NB, karar ağaçları ve KNN makine öğrenme yöntemleri kullanılmıştır. Kullanılan yöntemlerden en başarılısı \%97,2 doğru kestirim oranıly LSTM ve en başarısızı \%81,2 doğru kestirim oranıyla KNN yöntemidir.

Kristjanpoller ve Minutolo (2018) çalışmalarında yapay sinir ağları ve GARCH modelinin hibriti olan ANN - GARCH modeli ile Bitcoin fiyatı için oynaklık öngörüsü yapmışlardır. Çalışmada 13 Eylül 2011 - 26 Ağustos 2017 dönemi günlük veriler kullanılmıştır. Oynaklık temel olarak 22 günlük (1 aylık) getiri varyansıyla temsil edilmiştir. Ayrıca analizlerde 10 günlük ve 44 günlük varyans da kullanılmıştır. Modellerde Bitcoin fiyatlarına ilaveten 7 teknik indeks kullanılmıştır. Çalışmada farklı kombinasyonlardan oluşan 12 modelle öngörüler yapılmıştır. Sadece GARCH modelinin öngörüleri ile kurulan tüm modeller için hibrit model daha uygun MSE değerleri elde edilmesini sağlamıştır. Teknik indekslerin de dâhil edildiği modellerde de MSE değerleri küçülmüștür. Bu grupta en iyi hibrit modeller en az katman ve nöron içeren modellerdir. Son grupta ise teknik indekslere temel bileşenler analizi uygulanmıştır. Temel bileşen analizinin dâhil edilmesi öngörü performansını daha da artırmıştır.

da Silva Filho ve Maganini (2018) çalışmalarında Bitcoin fiyatının çok ölçekli yapısını araştırmışlardır. Çalışmada 14 Eylül 2011 - 20 Kasım 2017 dönemi 12 saatlik veriler kullanılmıştır. Çalışmada MFDFA yöntemi kullanılmıştır. Bitcoin getiri serisi çarpıklık ve basıklık açısından öncü hisse senedi piyasalarının getiri serisinden faklıdır. Bitcoin serisi çok ölçeklilik sergilemektedir. Çok ölçekliliğin kaynağı uzun aralıklı korelasyon ve kalın kuyruk dağılımdır. Ayrıca Bitcoin serisinin çok ölçeklilik dereceleri diğer finansal serilerden daha yüksektir. Çok ölçeklilik ile bu varlığa ait öngörülecek oynaklıklar ve değerler arasında korelasyon tespit edilmiştir.

Güleç vd. (2018) çalışmalarında başlıca kripto para birimlerinin işleyiş sürecini incelemişler; Bitcoin fiyatının döviz, hisse senedi emtia piyasaları ve faiz ile ilişkisini Granger nedensellik analizi ve Johansen eşbütünleşme testi bağlamında araştırmışlardır. Çalışmada Mart 2012 - Mayıs 2018 dönemi aylık veriler kullanılmıştır. Elde edilen bulgulara göre Bitcoin, faizin Granger nedenidir. Etki - tepki fonksiyonlarına göre Bitcoin fiyatındaki şoka en fazla tepki faiz değişkeni için elde edilmiş; ayrıca varyans ayrıştırmasına göre Bitcoin fiyatının faiz üzerindeki etkisinin oldukça yüksek olduğu tespit edilmiştir. 
Karasu vd. (2018) çalışmalarında Bitcoin fiyat öngörüsü yapmışlardır. Çalışmada 2012 2018 yılları arası günlük veriler kullanılmıştır. Öngörüler, doğrusal regresyon (LR) ve destek vektör makineleri (SVM) ile elde edilmiştir. Çalışmada farklı gecikme adımlarına göre hesaplanan MA ve WMA filtreleri için kapanış, en yüksek ve en düşük fiyat serileri kullanılarak kapanış fiyat öngörüsü yapılmıştır. SVM'de polinom ve doğrusal çekirdek fonksiyonları kullanılmıştır. En başarılı öngörüler 2 gecikmeli WMA filtreli polinom çekirdek fonksiyonlu SVM ile elde edilmiştir.

Aslan vd. (2018) çalışmalarında Bitcoin fiyatını eğri uydurma ve ANFIS yöntemleri ile öngörmüşlerdir. Çalışmada 23 Temmuz 2017 - 22 Temmuz 2018 dönemi günlük veriler kullanılmıştır. Her iki model için de uygun parametreleri belirlemek amacıyla farklı parametreler için sonuçlar elde edilerek karşılaştırılmıştır. ANFIS için en iyi sonuç 500 iterasyon ve 39 kuraldan oluşan modele göre, eğri uydurma için ise 19. dereceden polinom modeline göre en başarılı sonuçlar elde edilmiştir. İki yöntem karşılaştırıldığında ANFIS yönteminin daha iyi sonuç verdiği, \%4 - \%5 civarı hatalarla öngörü elde edilmesini sağladığı tespit edilmiştir.

Kanat ve Öget (2018) çalışmalarında Türkiye ve G7 ülkelerinin borsaları ile Bitcoin fiyatı arasındaki ilişkiyi araştırmışlardır. Çalışmada 1 Ocak 2013 - 26 Ocak 2018 dönemi günlük veriler kullanılmıştır. Analizler Jahansen eşbütünleşme testi, VECM ve Granger nedensellik testleri ile gerçekleştirilmiştir. Jahansen eşbütünleşme testi seriler arasında uzun dönem ilişkinin bulunduğunu göstermektedir. VECM modeline göre hata düzeltme mekanizmasının çalışmadığı tespit edilmiştir. Nedensellik testine göre İngiltere Borsası Bitcoin fiyatının; Bitcoin fiyatı ise ABD ve Kanada Borsaları'nın Granger nedenidir.

Ceylan vd. (2018) çalışmalarında Bitcoin ve Etherium para birimlerinin fiyat hareketlerinde baloncukları tespit etmeyi amaçlamışlardır. Kullanılan veriler Bitcoin için 1 Ocak 2015 - 31 Mart 2018; Etherium için ise 3 Ekim 2016 - 31 Mart 2018 dönemine ait günlük verilerdir. Çalışmada balonları tespiti GSADF yöntemi ile yapılmıştır. Çalışmada her iki para birimi için de birçok kısa süreli balon tespit edilmiştir. 2017 - 2018 aralığında ise daha uzun süreli balon tespit edilmiştir. $\mathrm{Bu}$ sonuç piyasalarda sürü psikolojisi olduğunun göstergesidir. Balonların spekülatif kaynaklı olduğu söylenebilir.

Şahin (2018) çalışmasında Bitcoin fiyat öngörüsü yapmayı amaçlamıştır. Veriler 2 Şubat 2012 - 9 Ocak 2018 dönemine ait günlük verilerdir. Çalışmada ARIMA ve YSA yöntemleri kullanılmıştır. Çalışmada ARIMA $(1,1,6)$ ve $\operatorname{MLP}(6,3,1)$ modelleri kullanılmıştır. ARIMA modeline ait durağan $R^{2} 0,413$ olarak hesaplanmıştır. MLP modeli için ise eğitim verisi için performans ölçütü $\% 99,79$; test performans1 ise \%99,83 olarak elde edilmiştir. Elde edilen bulgulara göre MLP modelinin ARIMA modeline göre daha başarılı olduğu belirtilmiştir.

Şahin ve Özkan (2018) çalışmalarında ARCH, GARCH, ARCHM, EGARCH ve TARCH yöntemleriyle Bitcoin getirileri için asimetrik oynaklığı belirlemeyi amaçlamışlardır. Çalışmada 1 Ocak 2015 - 11 Şubat 2018 dönemine ait günlük veriler kullanılmıştır. Uygulanan testler Bitcoin getiri serisinin ARCH etkisi içerdiği tespit edilmiştir. Yapılan analizlerde en uygun modelin TARCH modeli olduğu belirlenmiştir. TARCH için ise en uygun modelin TARCH $(1,1)$ olduğu belirlenmiştir. Bitcoin'in merkezi olmaması yüksek oynaklığa neden olmaktadır.

Balcilar vd. (2017) çalışmalarında Bitcoin işlem hacmi ile oynaklığı ve getirisi arasındaki nedensel ilişkiyi parametrik olmayan bir nedensellik testi olan kantil nedensellik testi ile araştırmışlardır. Çalışmada 19 Aralık 2011 - 25 Nisan 2016 dönemi günlük veriler kullanılmıştır. Çalışmada getirilerin karesi oynaklık ölçüsü olarak kullanılmıştır. Standart lineer Granger nedensellik testi hacim ile getiri arasındaki nedensel ilişkiyi tespit edememiştir. Doğrusallık testleri getiri ve hacim arasındaki ilişkinin doğrusal olmadığını göstermektedir. Ayrıca seride çoklu yapısal kırılma tespit edilmiştir. 0,25 ve $0,75^{\prime}$ 'lik kantiller için hacim, getirinin Granger nedenidir. Fakat aynı durum kuyruklar için geçerli değildir. $\mathrm{Bu}$ sonuçlar hacmin, getirinin öngörüsünde kullanılabileceğini, oynaklığın öngörüsünde kullanılamayacağını göstermektedir. 
Li ve Wang (2017) çalışmalarında ekonomik ve teknolojik faktörleri de dikkate alarak Bitcoin fiyatını belirlemeyi amaçlamışlardır. Çalışmada 1 Ocak 2011 - 31 Aralık 2014 dönemi günlük veriler kullanılmıştır. Analizler ARDL ve VECM modelleriyle gerçekleştirilmiştir. Analizler teknolojik ve ekonomik faktörlerin Bitcoin fiyatı üzerinde etkili olduğunu göstermektedir. Piyasa fiyatı madencilik maliyetine bağlı olsa da madencilik teknolojisi daha verimli hale geldikçe madencilik zorluklarının uzun vadeli etkisi zamanla azalmaktadır. Analizlerin ilk dönemleri için fiyatlar spekülatif faktörlerden etkilenmektedir ve ekonomik faktörlerden etkilenmemektedir. İleri dönemler için ise tersi geçerlidir.

\section{Veriler ve Yöntem}

Çalışmada 01 Ocak 2017 - 29 Şubat 2020 dönemi, 1155 günlük Bitcoin fiyat serisi $\left(P_{t}\right)$ kullanılmıştır. Öngörüler GARCH (Genelleştirilmiş Otoregresif Koşullu Değişen Varyans) modeli ve DVM - EKK (Destek Vektör Makineleri En küçük Kareler) regresyonu ile elde edilmiştir. Kullanılan veriler https://coinmarketcap.com sayfasından elde edilmiştir. Aşağıdaki tabloda Bitcoin fiyat serisine ait betimleyici istatistikler ve aşağıdaki şekilde Bitcoin fiyat serisine ait grafik sunulmuştur.

Tablo 1: Bitcoin Fiyat Serisi Tanımlayıcı İstatistikler

\begin{tabular}{lccccccc}
\hline & Ortalama & En Büyük & $\begin{array}{c}\text { En } \\
\text { Küçük }\end{array}$ & $\begin{array}{c}\text { Standart } \\
\text { Sapma }\end{array}$ & Varyans & Çarpıklık & Basıklık \\
\hline Bitcoin Fiyatları & 6462.96 & 19497.40 & 777.76 & 3496.01 & 12222084.93 & 0.43 & 3.26 \\
\hline
\end{tabular}

Bitcoin Fiyatları

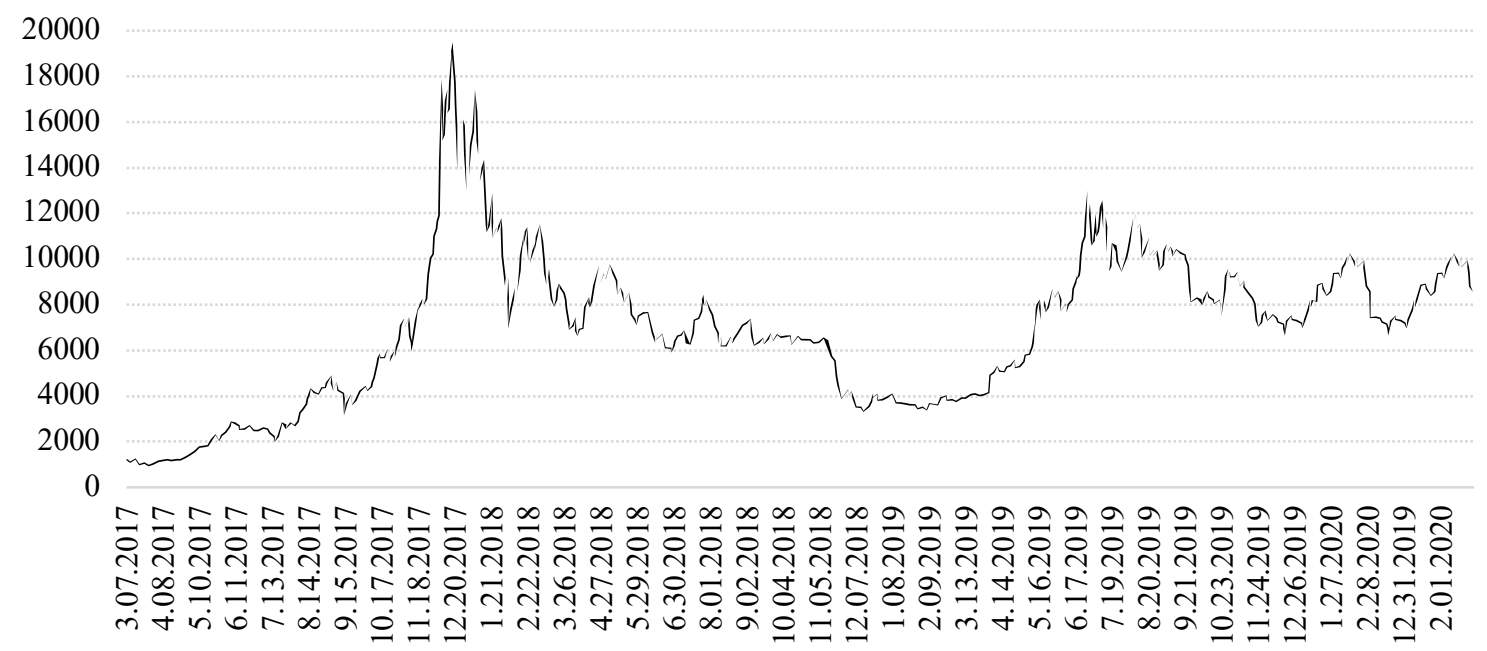

Şekil 1. Bitcoin Fiyat Serisi

Çalışmada her iki yöntem için de son 1, 2 ve 3 aya ait gözlemler çıkarılarak modeller tahmin edilmiş, sonrasında tahmin edilen modeller kullanılarak modelin tahmininde kullanılan dönemlere ait örneklem içi ve modelin tahmininde kullanılmayan dönemlere ait örneklem dışı kestirimler elde edilmiştir. Nihayetinde tüm modeller için kestirim performansı değerlendirme kriterleri hesaplanmıştır. $A_{t}$, gözlenen değer ve $P_{t}$ kestirim olmak üzere modellerin kestirim performanslarını değerlendirmede kullanılan kriterler aşağıdaki eşitliklerle hesaplanmaktadır:

MSE $=\frac{1}{n} \sum_{t=1}^{T}\left(A_{t}-P_{t}\right)^{2}$ 


$$
\begin{aligned}
& R^{2}=1-\frac{\sum_{t=1}^{T}\left(A_{t}-P_{t}\right)^{2}}{\sum_{t=1}^{T} A_{t}^{2}} \\
& \text { RMSE }=\sqrt{\frac{1}{n} \sum_{t=1}^{T}\left(A_{t}-P_{t}\right)^{2}} \\
& \text { NRMSE }=\frac{\text { RMSE }}{\operatorname{maks}(\mathrm{A})-\min (A)} \\
& \text { MAPE }=\frac{1}{n} \sum_{t=1}^{T}\left|\frac{A_{t}-P_{t}}{A_{t}}\right| 100
\end{aligned}
$$

\subsection{GARCH Modeli:}

Finans alanında yapılan çalışmalarda amaç finansal araçlar ile ekonomik göstergeler arasındaki ilişki, finansal araçlar arasındaki ilişki ve finansal araçların gelecek değerlerinin öngörüsü olabilmektedir. Amaç öngörü olduğunda modellerde bazı ekonomik ve finansal göstergeler kullanılabileceği gibi sadece öngörülmesi amaçlanan serinin geçmiş dönem değerlerinin (AR) ve modele ait kalıntıların (MA) yer aldığı modeller de kullanılabilmektedir. Modele finansal ve ekonomik göstergelerin dâhil edilmesi doğru faktörlerin belirlenmesinde yaşanan güçlüklerin yanında öngörü modellerinde bu finansal ve ekonomik göstergelerin gelecek değerlerinin de öngörülmesini gerektirmeleri gibi bazı zorluklar içermektedir. Bu nedenlerle sadece öngörülmesi amaçlanan serinin geçmiş dönem değerlerinin ve modele ait kalıntıların yer aldığı modeller daha cazip olabilmektedir. Bu bağlamda zaman serilerinin gelecek dönem öngörülerinde AR, MA, ARMA ve ARIMA gibi yöntemler sıklıkla kullanılmaktadır. Fakat özellikle getiri gibi finansal seriler bu modellerle öngörülmek istediğinde yöntemlerin önemli bir varsayımı olan sabit varyans varsayımı ihlal edilebilmektedir. Böyle bir durumda değişen varyansın da dikkate alınması gerekmektedir. $\mathrm{Bu}$ problem en genel ifadesiyle modelin hata teriminin, hataların geçmiş dönem değerleriyle ilişkili olduğu varsayımıyla kurulan ARCH modelinin ve ARCH modelinin hata terimine hata varyansının da eklenmesi ile kurulan GARCH modellerinin kullanılmasıyla ortadan kaldırılabilmektedir. ARCH modeli aşağıdaki gibi ifade edilebilir (Engle, 1982: 988):

$$
\begin{aligned}
& y_{t}=\epsilon_{t} h_{t}^{1 / 2} \\
& h_{t}=\alpha_{0}+\alpha_{1} y_{t-1}^{2}
\end{aligned}
$$

Bu denklemde $\psi_{t}, t$ döneminde mevcut olan bilgi kümesi olmak üzere $y_{t} \mid \psi_{t-1} \sim N\left(0, h_{t}\right)$ ve $V\left(\epsilon_{t}\right)=1$ 'dir. $\operatorname{ARCH}(p)$ süreci için varyans fonksiyonu aşağıdaki gibidir:

$$
h_{t}=\alpha_{0}+\sum_{i=1}^{p} \alpha_{i} y_{t-i}^{2}
$$

GARCH modelinde ise hata varyans fonksiyonu artıkların gecikmelerinin karelerini ve varyansin gecikmelerini de içerecek şekilde yazılır (Bollerslev, 1986: 309):

$$
h_{t}=\alpha_{0}+\alpha_{1} \epsilon_{t-1}^{2}+\beta_{1} y_{t-1}^{2}
$$

$\operatorname{GARCH}(p, q)$ süreci için varyans fonksiyonu ise aşağıdaki gibidir:

$$
h_{t}=\alpha_{0}+\sum_{i=1}^{q} \alpha_{i} \epsilon_{t-i}^{2}+\sum_{i=1}^{p} \beta_{i} h_{t-i}
$$




\subsection{DVM - EKK Regresyonu:}

Destek vektör makinaları (DVM) istatistiki öğrenme teorisi kullanarak öğrenme, sınıflandırma, kümeleme, yoğunluk tahmini ve regresyon tahmini için kullanılabilen bir eğitme algoritmasıdır (Kaytez, 2012: 68). DVM diğer öğrenme algoritmalarına göre hem uygulama kolaylığına sahiptir hem de daha iyi performans sağlamaktadır (Cortes ve Vapnik, 1995: 273-297). Doğrusal olmayan ilişkilerin modellenmesinde de kullanılabilmesi önemli avantajlarındandır. Gözlem sayısının çok az olduğu durumlarda da kullanılabilmektedir (Kaytez, 2012: 68). DVM'nin eğitimi kuadratik optimizasyon içerdiğinden girdilere bağlı olarak tek bir çıktı elde etmeyi garanti eder (Karthika vd., 2017: 4). Destek vektör makinaları kullanılarak hata karelerinin minimizasyonuna dayanan doğrusal olmayan regresyon modeli tahmin edilebilmektedir. Bu yöntem Destek Vektör Makinaları - En Küçük Kareler (DVM - EKK) Regresyonu olarak anılmaktadır. DVM - EKK standart DVM'nin eşitlik sınırlamalarına dayanan optimizasyon problemi kurmak için en küçük kareler kayıp fonksiyonunu kullanan bir alternatifidir (Kaytez vd., 2015: 433). Destek vektör öğrenme algoritması, doğrusal olmayan regresyon modelinde hata fonksiyonunu minimize eder (Haykin, 1999: 366). d'nin sabit çıktı, $x^{\prime}$ 'in girdi vektörü olduğu modeli ele alalım:

$d=f(x)+v$

Burada sabit değerli doğrusal olmayan fonksiyon $f(x)$ koşullu beklenen değer $(E[Y \mid x])$ şeklinde tanımlanmıştır. $D$ ise $d$ ile ifade edilen değişkenin gerçekleşen değeri olan bir rassal değişkendir. Hata terimi $v, x$ girdi vektöründen istatistiki olarak bağımsızdır. $f($.$) ve v$ bilinmemekte, sadece girdi ve çıktı değişkenlerine ait $N$ gözlem bulunmaktadır (Haykin, 1999: 363).

$y$ ile gösterilen $d$ 'nin bir tahmini olduğunu varsayalım. $y$ bir grup doğrusal olmayan temel fonksiyonlar biçiminde aşağıdaki gibi açılmaktadır:

$y=\sum_{j=0}^{m_{\Perp}} w_{j} \varphi_{j}(x)=w^{T} \varphi(x)$

$\varphi(x)=\left[\varphi_{0}(x), \varphi_{1}(x), \ldots, \varphi_{m_{1}}(x)\right]^{T}$

$w=\left[w_{0}, w_{1}, \ldots, w_{m_{1}}\right]^{T}$

Burada $\varphi_{0}(x)=1$ olduğu varsayılmaktadır. Bu durumda $w_{0}$ sapma $b$ 'yi temsil eder. $w$ ve $b$ değerleri hesaplanması gereken regresyon parametreleridir (Xuemei vd., 2009: 56). Bu ifade ampirik riski minimize edecek biçimde tekrar çözülmelidir:

$R_{\text {amp }}=\frac{1}{N} \sum_{i=1}^{N} L_{E}\left(d_{i} y_{i}\right)$

K1sit ise:

$\|w\|^{2} \leq c_{0}$

biçimindedir. Burada $c_{0}$ bir sabittir. $L_{\varepsilon}\left(d_{i} y_{i}\right)$ ise $\epsilon$ önceden belirlenmiş parametre olmak üzere aşağıda gösterilen $\epsilon$-duyarsız kayıp fonksiyonudur:

$L_{E}\left(d_{i} y_{i}\right)=\left\{\begin{array}{cc}\mid d-y \|-\epsilon, & \mid d-y \| \geq \epsilon \text { ise } \\ 0, & \text { diğer durumlarda }\end{array}\right.$

Burada $\epsilon$-duyarsız kayıp fonksiyonunun kullanılma nedeni aşırı değerlerin bulunması ve hata teriminin dağılımının uzun kuyruklu olması durumunda dirençli tahminler elde edilmesini sağlamaktır (Haykin, 1999: 362). DVM optimum hiper düzlemi elde etmeye ve $\epsilon$-duyarsız kayıp fonksiyonunu kullanılarak hatayı minimize etmeyi sağlar (Fan vd., 2016: 960). 


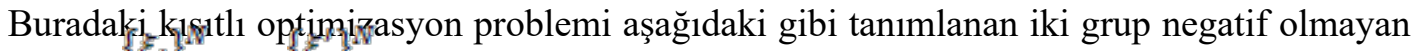
aylak değişken ${ }^{\left\{\xi_{i}\right\}_{i=1}} \mathrm{ve}^{\left[\xi_{i}\right\}_{i=1}}$ eklenerek tekrar yazılabilir.

$$
\begin{array}{ll} 
& d_{i}-w^{T} \varphi\left(x_{i}\right) \leq \epsilon+\xi_{i}, \quad i=1,2, \ldots, N \\
w^{T} \varphi\left(x_{i}\right)-d_{i} \leq \epsilon+\xi_{i}^{s}, & i=1,2, \ldots, N \\
\xi_{i} \geq 0, \quad i=1,2, \ldots, N & \\
\xi_{i}^{\prime} \geq 0, \quad i=1,2, \ldots, N &
\end{array}
$$

$\xi_{\bar{i}}$ ve $\xi_{i}^{r} \in$-duyarsız kayıp fonksiyonunu ifade eder. Böylece bu kısıtlı optimizasyon problemi yukarıdaki kısıtlar altında:

$$
\Phi\left(w, \xi_{i}, \xi_{i}^{\prime}\right)=c\left(\sum_{i=1}^{w}\left(\xi_{i}+\xi_{i}^{\prime}\right)\right)+\frac{1}{2} w^{T} w
$$

şeklindeki maliyet fonksiyonu minimizasyonuna denktir. $\Phi\left(w, \xi_{i}, \xi_{i}^{\prime}\right)$ fonksiyonuna $w^{T} w / 2$ terimi eklenerek yukarıdaki $\|w\|^{2} \leq c_{0}$ kısıdının gerekliliğini ortadan kaldırılmıştır. Yukarıdaki eşitlikte $C$ kullanıcı tarafindan belirlenen bir parametredir (Haykin, 1999: 363). gibidir:

Bu durumda $\alpha_{i}$ ve $\alpha_{i}^{z}$ Lagrange çarpanları olmak üzere Lagrange fonksiyonu aşağıdaki

$$
\begin{aligned}
I\left(w, \xi_{i}, \xi_{i}^{g}, \alpha, \alpha^{\prime}, \gamma, \gamma^{\prime}\right) & =C\left(\sum_{i=1}^{N}\left(\xi_{i}+\xi_{i}^{v}\right)\right)+\frac{1}{2} w^{T} w-\sum_{i=1}^{N} \alpha_{i}\left[w^{T} \varphi\left(x_{i}\right)-d_{i}+\epsilon+\xi_{i}^{\prime}\right] \\
& -\sum_{i=1}^{N} \alpha_{i}^{g}\left[d_{i}-w^{T} \varphi\left(x_{i}\right)+\epsilon+\xi_{i}\right]-\sum_{i=1}^{N}\left(\gamma \xi_{i}+\gamma^{\prime} \xi_{i}^{\prime}\right)
\end{aligned}
$$

Kuadratik optimizasyon probleminin çözümüyle $w$ aşağıdaki gibi tahmin edilir:

$$
w=\sum_{i=1}^{w}\left(\alpha_{i}-\alpha_{i}^{r}\right) \varphi\left(x_{i}\right)
$$

DVM regresyon denklemi aşağıdaki gibi elde edilir:

$$
f(x)=\sum_{i=1}^{N}\left(\alpha_{i}-\alpha_{i}^{r}\right) K\left(x_{i}, x\right)+b
$$

$\mathrm{Bu}$ denklemde $K\left(x_{i}, x\right)$ çekirdek fonksiyondur. Çekirdek fonksiyonun farklı biçimleri bulunmaktadır. En sık kullanılanları Gaussian radial basis fonksiyon ve polynomial çekirdektir (Fan vd., 2016: 961). DVM'nin EKK - DVM versiyonunda ise kısitlı optimizasyon problemi:

$$
\Phi\left(w, \xi_{i}, \xi_{i}^{\prime}\right)=\zeta \frac{1}{2}\left(\sum_{i=1}^{w}\left(\xi_{i}+\xi_{i}^{\prime}\right)\right)+\frac{1}{2} w^{T} w
$$

biçimindedir. Eşitlik kısıtları:

$$
\begin{array}{ll} 
& d_{i}-w^{T} \varphi\left(x_{i}\right)=1+\xi_{i}, \quad i=1,2, \ldots, N \\
w^{T} \varphi\left(x_{i}\right)-d_{i}=1+\xi_{i}^{j}, \quad i=1,2, \ldots, N &
\end{array}
$$

$\mathrm{Bu}$ durumda Lagrange fonksiyonu aşağıdaki gibidir: 


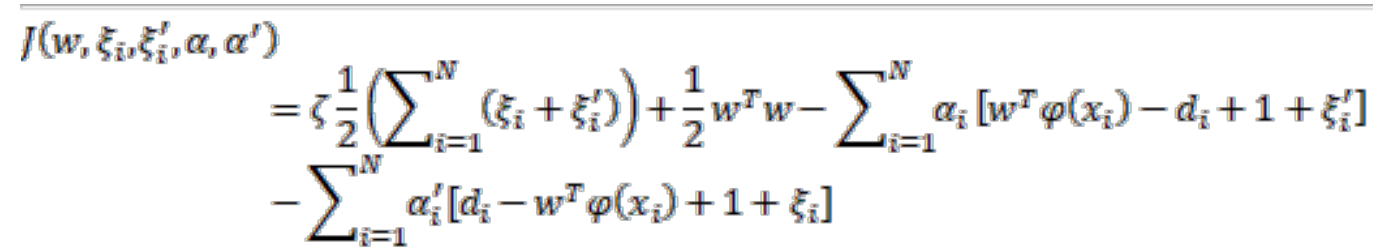

$\alpha_{i}$ ve $\alpha_{i}^{z}$ Lagrange çarpanları DVM için sadece pozitif değerler alabilirken, EKK - DVM için pozitif veya negatif değerler alabilmektedir (Suykens ve Vandewalle, 1999: 295-296). EKK - DVM, bu formülasyon farkının yanında eğitim zamanı avantajı da içermektedir (Kaytez, 2012: 85).

\section{Bulgular ve Tartışma}

$\mathrm{Bu}$ çalışmanda klasik zaman serisi modellerinden GARCH modeli ve bir makine öğrenme yöntemi olan DVM - EKK yöntemiyle Bitcoin fiyat serisine ait kestirimler elde edilmiş, model performansları karşılaştırılmıştır. Bu çalışmada modellerin tahmininde amaç geleceğe ait öngörülerin elde edilmesi olduğundan örneklem içi performansların karşılaştırılması yanıltıcı olacaktır. Bu nedenle yorumlar örneklem dışı performanslara göre yapılmıştır. Ayrıca modellerin karşılaştırılmasında daha anlamlı ve yorumu daha anlaşılır olduğundan MAPE oranları kullanılarak modeller karşılaştırılmış ve yorumlanmıştır.

\subsection{GARCH Modeli Sonuçları:}

GARCH modelinin tahmini için serinin durağan olması gerektiğinden, çalışmada kullanılan seriye Augmented Dickey - Fuller (ADF), Phillips - Perron (PP) ve Kwiatkowski - Phillips Schmidt - Shin (KPSS) birim kök testleri uygulanmıştır. Bitcoin fiyat serisine ait durağanlık test sonuçları aşağıdaki tabloda sunulmuştur.

Tablo 2: Birim Kök Testi Sonuçları

\begin{tabular}{lcccccc}
\hline & \multicolumn{3}{c}{$\boldsymbol{P}_{\boldsymbol{t}}$} & \multicolumn{3}{c}{ dlog $\left(\boldsymbol{P}_{\boldsymbol{t}}\right)$} \\
\cline { 2 - 7 } & ADF & PP & KPSS & ADF & PP & KPSS \\
\hline Sabitli & -2.0660 & -2.0955 & 1.1616 & $-33.9244^{*}$ & $-33.9532^{*}$ & $0.3156^{*}$ \\
Sabitli ve Trendli & -2.1035 & -2.1428 & 0.3719 & $-33.9688^{*}$ & $-33.9902^{*}$ & $0.1140^{*}$ \\
Sabitsiz & -0.4421 & -0.4643 & & $-33.8736^{*}$ & $-33.9168^{*}$ & \\
\hline
\end{tabular}

*, \%1 seviyesinde durağanlığg göstermektedir.

Tabloda görüldüğü gibi $P_{t}$ serisi tüm testlere göre seviyede durağan değildir. Bu nedenle serinin doğal logaritmasının birinci farkı alınarak

$$
\operatorname{dlog}\left(P_{t}\right)=\log \left(P_{t}\right)-\log \left(P_{t-1}\right)
$$

eşitliğiyle $\operatorname{dlog}\left(P_{t}\right)$ serisi elde edilmiş ve bu seriye durağanlık testleri uygulanmıştır. Seri bu haliyle logaritmik getridir. $\operatorname{dlog}\left(P_{t}\right)$ serisi tüm testlere göre durağandır. GARCH modelinin tahmininde $\operatorname{dlog}\left(P_{t}\right)$ serisi kullanılmıştır.

GARCH modelinin fonksiyonel yapısının belirlenmesi önemli bir husustur. Doğru kurulmamış bir model hatalı öngörüler elde edilmesine yol açacaktır. Çalışmada öncelikle ARIMA modelleri tahmin edilmiş ancak modelin ARCH etkisi içerdiği tespit edilmiştir. Bu nedenle hem değişen varyans hem de otokorelasyon probleminden arındırılmış bir model elde edilmesi amaçlanmıştır. Farklı alternatifler için yapılan denemelerde $\operatorname{GARCH}(1,1)$ modelinin değişen varyans ve otokorelasyon içermediği tespit edilmiş ve öngörülerde bu model kullanılmıştır. Öngörüler dlog $\left(P_{t}\right)$ serisi için elde edilmiş sonrasında $P_{t}$ serisine ait öngörüler elde edilmiş, performans kriterleri $P_{t}$ serisinin öngörüleri için hesaplanmış ve aşağıdaki tabloda sunulmuştur: 
Tablo 3: GARCH Modeli Öngörü Performans Kriterleri

\begin{tabular}{|c|c|c|c|c|c|c|}
\hline & $\begin{array}{l}\text { Öngörü } \\
\text { Periyotu }\end{array}$ & MSE & $\mathbf{R}^{2}$ & RMSE & NRMSE & MAPE \\
\hline \multirow{3}{*}{ 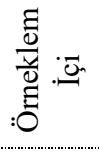 } & 1 Ay & 143756.06 & 0.9974 & 379.15 & 0.0204 & 2.9360 \\
\hline & 2 Ay & 146456.87 & 0.9974 & 382.70 & 0.0206 & 2.9732 \\
\hline & 3 Ay & 150383.69 & 0.9973 & 387.79 & 0.0209 & 3.0189 \\
\hline \multirow{3}{*}{ 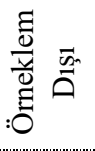 } & 1 Ay & 60427.82 & 0.9994 & 245.82 & 0.1424 & 1.9653 \\
\hline & 2 Аy & 57433.50 & 0.9993 & 239.65 & 0.0717 & 2.0456 \\
\hline & 3 Ay & 47576.74 & 0.9993 & 218.12 & 0.0592 & 1.8728 \\
\hline \multirow{3}{*}{ 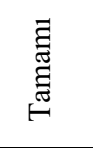 } & 1 Ay & 141539.07 & 0.9975 & 376.22 & 0.0203 & 2.9101 \\
\hline & 2 Ay & 141556.50 & 0.9975 & 376.24 & 0.0203 & 2.9222 \\
\hline & 3 Ay & 141800.72 & 0.9975 & 376.56 & 0.0203 & 2.9232 \\
\hline
\end{tabular}

Örneklem dışı öngörü başarısı haricinde, öngörü periyotu uzadıkça öngörü performansı düşmektedir. MAPE oranlarına göre örneklem dışı başarılı öngörü oran1 1 ay için \%998,0347; 2 ay için $\% 97,9544$ ve 3 ay için $\% 98,1272$ 'dir. En iyi performans 3 ay için elde edilmiştir. $P_{t}$ serisi için GARCH modelinin öngörü performansları oldukça iyidir.

\subsection{DVM - EKK Regresyonu Sonuçları:}

DVM - EKK regresyonunda parametrik yöntemler gibi anlamlılık testleri yapılamadığından gecikme uzunluğu farklı denemeler yapılarak belirlenmiştir. Gecikme uzunluğunun artırılması DVM - EKK regresyonunun öngörü performansını artırdığından bu modelde 65 günlük gecikme kullanılmıştır. Ayrıca bu tarz finansal seriler oynaklık içerdiğinden modelde (Garman ve Klass, 1980: 74) tarafından önerilen aşağıdaki gibi hesaplanan parametrik olmayan oynaklık göstergeleri farklı gecikme uzunlukları ile kullanılmıştır.

$\sigma_{t}^{2}=\frac{1}{2}\left(H_{t}-L_{t}\right)^{2}-(2 \log (2)-1)\left(P_{t}-O_{t}\right)^{2}$

Burada $H_{t}$, en yüksek fiyat; $L_{t}$, en düşük fiyat; $P_{t}$, kapanış fiyatı ve $O_{t}$, kapanış fiyatını göstermektedir. Bu modelde de seriler dönüştürülerek kullanılmıştır. Serilerin öncelikle logaritması alınmış ve seriler aşağıdaki gibi ölçeklendirilerek $[-1,1]$ aralığında değerler almaları sağlanmıştır.

$X_{t}^{*}=2 \frac{X_{t}-X_{\min }}{X_{\operatorname{maks}}-X_{\min }}$

Tablo 4: DVM - EKK Modeli Öngörü Performans Kriterleri

\begin{tabular}{|c|c|c|c|c|c|c|c|}
\hline & & Oynaklık & MSE & $\mathbf{R}$ & RMSE & NRMSE & MAPE \\
\hline \multirow{13}{*}{ 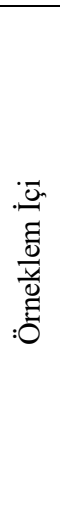 } & $1 \mathrm{Ay}$ & 0 & 2857.52 & 0.9999 & 53.46 & 0.0029 & 0.5266 \\
\hline & 1 Ay & 1 & 7366.16 & 0.9999 & 85.83 & 0.0046 & 0.8268 \\
\hline & 1 Ay & 2 & 14249.22 & 0.9997 & 119.37 & 0.0064 & 1.1664 \\
\hline & 1 Ay & 3 & 125596.50 & 0.9978 & 354.40 & 0.0191 & 2.8520 \\
\hline & 1 Ay & 4 & 123018.63 & 0.9978 & 350.74 & 0.0189 & 2.8321 \\
\hline & $2 \mathrm{Ay}$ & 0 & 3689.76 & 0.9999 & 60.74 & 0.0033 & 0.5981 \\
\hline & 2 Ay & 1 & 4789.78 & 0.9999 & 69.21 & 0.0037 & 0.6698 \\
\hline & 2 Ay & 2 & 11186.82 & 0.9998 & 105.77 & 0.0057 & 1.0504 \\
\hline & 2 Ay & 3 & 75468.97 & 0.9986 & 274.72 & 0.0148 & 2.3969 \\
\hline & $2 \mathrm{Ay}$ & 4 & 89644.36 & 0.9984 & 299.41 & 0.0161 & 2.5643 \\
\hline & $3 \mathrm{Ay}$ & 0 & 4436.02 & 0.9999 & 66.60 & 0.0036 & 0.6571 \\
\hline & 3 Ay & 1 & 3229.58 & 0.9999 & 56.83 & 0.0031 & 0.5496 \\
\hline & 3 Ay & 2 & 17001.60 & 0.9997 & 130.39 & 0.0070 & 1.2617 \\
\hline
\end{tabular}




\begin{tabular}{|c|c|c|c|c|c|c|c|}
\hline & 3 Аy & 3 & 134844.03 & 0.9976 & 367.21 & 0.0198 & 2.9314 \\
\hline & 3 Ay & 4 & 122975.53 & 0.9978 & 350.68 & 0.0189 & 2.8465 \\
\hline \multirow{15}{*}{ 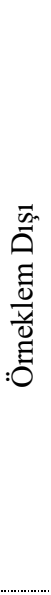 } & 1 Ay & 0 & 1628070.60 & 0.9825 & 1275.96 & 0.7390 & 9.5215 \\
\hline & 1 Ay & 1 & 361942.02 & 0.9961 & 601.62 & 0.3485 & 5.1016 \\
\hline & $1 \mathrm{Ay}$ & 2 & 376209.43 & 0.9960 & 613.36 & 0.3553 & 5.0524 \\
\hline & $1 \mathrm{Ay}$ & 3 & 321447.75 & 0.9965 & 566.96 & 0.3284 & 4.6577 \\
\hline & $1 \mathrm{Ay}$ & 4 & 336751.35 & 0.9964 & 580.30 & 0.3361 & 4.6950 \\
\hline & $2 \mathrm{Ay}$ & 0 & 2655259.05 & 0.9674 & 1629.50 & 0.4878 & 16.4729 \\
\hline & 2 Ay & 1 & 208510.48 & 0.9974 & 456.63 & 0.1367 & 3.8693 \\
\hline & 2 Ay & 2 & 2583020.38 & 0.9683 & 1607.18 & 0.4811 & 14.6145 \\
\hline & 2 Ay & 3 & 15263594.49 & 0.8128 & 3906.87 & 1.1695 & 37.2213 \\
\hline & $2 \mathrm{Ay}$ & 4 & 6245754.10 & 0.9131 & 2499.15 & 0.6781 & 20.0938 \\
\hline & $3 \mathrm{Ay}$ & 0 & 4685288.50 & 0.9348 & 2164.55 & 0.5873 & 19.9116 \\
\hline & 3 Ay & 1 & 15520671.99 & 0.7839 & 3939.63 & 1.0689 & 37.8450 \\
\hline & 3 Ay & 2 & 2626515.49 & 0.9634 & 1620.65 & 0.4397 & 14.3596 \\
\hline & 3 Ay & 3 & 644711.25 & 0.9910 & 802.94 & 0.2179 & 8.5126 \\
\hline & 3 Ay & 4 & 760341.00 & 0.9894 & 871.98 & 0.2366 & 8.8907 \\
\hline \multirow{15}{*}{ 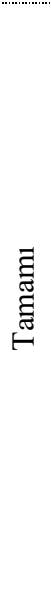 } & $1 \mathrm{Ay}$ & 0 & 46097.14 & 0.9992 & 214.70 & 0.0116 & 0.7659 \\
\hline & 1 Ay & 1 & 16799.83 & 0.9997 & 129.61 & 0.0070 & 0.9406 \\
\hline & $1 \mathrm{Ay}$ & 2 & 23879.36 & 0.9996 & 154.53 & 0.0083 & 1.2698 \\
\hline & $1 \mathrm{Ay}$ & 3 & 130807.22 & 0.9977 & 361.67 & 0.0195 & 2.9001 \\
\hline & $1 \mathrm{Ay}$ & 4 & 128705.09 & 0.9977 & 358.75 & 0.0193 & 2.8817 \\
\hline & $2 \mathrm{Ay}$ & 0 & 149647.71 & 0.9974 & 386.84 & 0.0208 & 1.4720 \\
\hline & $2 \mathrm{Ay}$ & 1 & 16003.76 & 0.9997 & 126.51 & 0.0068 & 0.8459 \\
\hline & 2 Ay & 2 & 152755.64 & 0.9973 & 390.84 & 0.0211 & 1.7971 \\
\hline & 2 Ay & 3 & 911512.58 & 0.9840 & 954.73 & 0.0514 & 4.3138 \\
\hline & $2 \mathrm{Ay}$ & 4 & 603594.81 & 0.9894 & 776.91 & 0.0419 & 4.0278 \\
\hline & $3 \mathrm{Ay}$ & 0 & 395222.79 & 0.9931 & 628.67 & 0.0339 & 2.2646 \\
\hline & 3 Ay & 1 & 1298722.48 & 0.9773 & 1139.62 & 0.0614 & 3.6633 \\
\hline & 3 Ay & 2 & 234860.10 & 0.9959 & 484.62 & 0.0261 & 2.3552 \\
\hline & 3 Ay & 3 & 177410.93 & 0.9969 & 421.20 & 0.0227 & 3.3973 \\
\hline & $3 \mathrm{Ay}$ & 4 & 176186.78 & 0.9969 & 419.75 & 0.0226 & 3.3511 \\
\hline
\end{tabular}

Öngörüler elde edildikten sonra seriler yukarıdaki formülasyona göre tekrar orijinal hallerine dönüştürülmüştür. Çekirdek fonksiyonu olarak Radyal Tabanlı Fonksiyon kullanılmıştır. $C$ ve $\sigma^{2}$ DVM -EKK modelinin eğitimi ile belirlenmiştir. Model tahmini MAE kriterine göre 10'lu çapraz doğrulama ile yapılmıştır. $P_{t}$ serisinin öngörüleri için performans kriterleri hesaplanmış ve Tablo 4'te sunulmuştur.

Modellere ait öngörü performansları ve oynaklık değişkeninin etkisi örneklem içi ve örneklem dışı farklılaşmaktadır. Genel olarak değerlendirecek olursa DVM - EKK modelinin örneklem içi çok başarılı kestirimler elde edilmesini sağladığı görülmektedir. Örneklem dış1 performans ise nispeten başarısızdır. Bu durum modelin aşırı öğrendiği şeklinde yorumlanabilir. 1 aylık öngörülerde en başarılı sonuçlar 3 oynaklık teriminin $(t, t-1$ ve $t-2$ dönemleri) kullanıldığı modelle elde edilmiştir. 2 aylık öngörülerde en başarılı sonuçlar 1 oynaklık teriminin ( $t$ dönemi) kullanıldığı modelle elde edilmiștir. 3 aylık öngörülerde en başarılı sonuçlar ise 3 oynaklık teriminin ( $t, t-1$ ve $t-2$ dönemleri) kullanıldı ̆̆ modelle elde edilmiştir. En başarılı modellere göre değerlendirilecek olursa MAPE oranlarına göre örneklem dışı başarılı öngörü oranı 1 ay için $\% 95,3423 ; 2$ ay için $\% 96,1307$ ve 3 ay için \%91,4874'tür. En iyi performans 2 ay için elde edilmiştir. Bitcoin fiyat serisi gibi aşırı belirsizlik içeren bir seri için örneklem dışı performanslar oldukça başarılıdır.

\subsection{GARCH ve DVM - EKK Model Sonuçlarının Karşılaştırılması:}

Bitcoin fiyat serisi belirsizliğin oldukça fazla olduğu bir seridir. Bu durum, bu seri için özellikle örneklem dışı başarılı öngörülerin elde edilmesini zorlaştırmaktadır. Buna rağmen her iki 
model için de elde edilen sonuçlar tatmin edici seviyelerdedir. GARCH ve DVM - EKK modelleri için MAPE oranlarına göre örneklem dışı başarılı öngörü oranları sırasıyla 1 ay için \%98,0347 $\% 95,3423 ; 2$ ay için $\% 97,9544$ - \%96,1307 ve 3 ay için $\% 98,1272-\% 91,4874$ 'dir. GARCH modeli her üç periyot için de daha başarılı sonuçlar elde edilmesini sağlamıştır. Tüm örneklem ve örneklem dış1 kestirimlere ait grafikler Şekil 1 ve Şekil 2'de sunulmuştur.

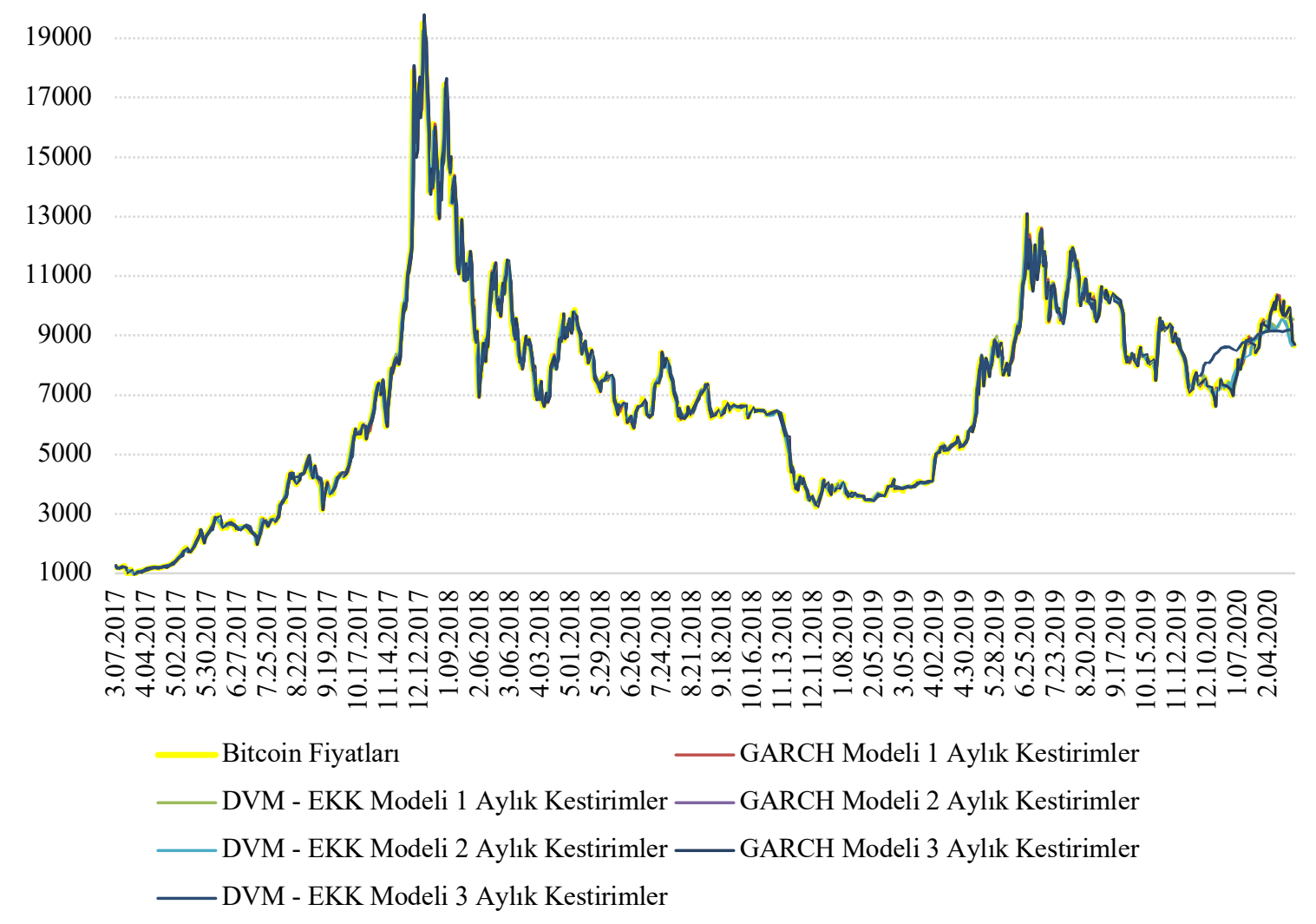

Şekil 2. Örneklemin Tamamı İçin Kestirimler 


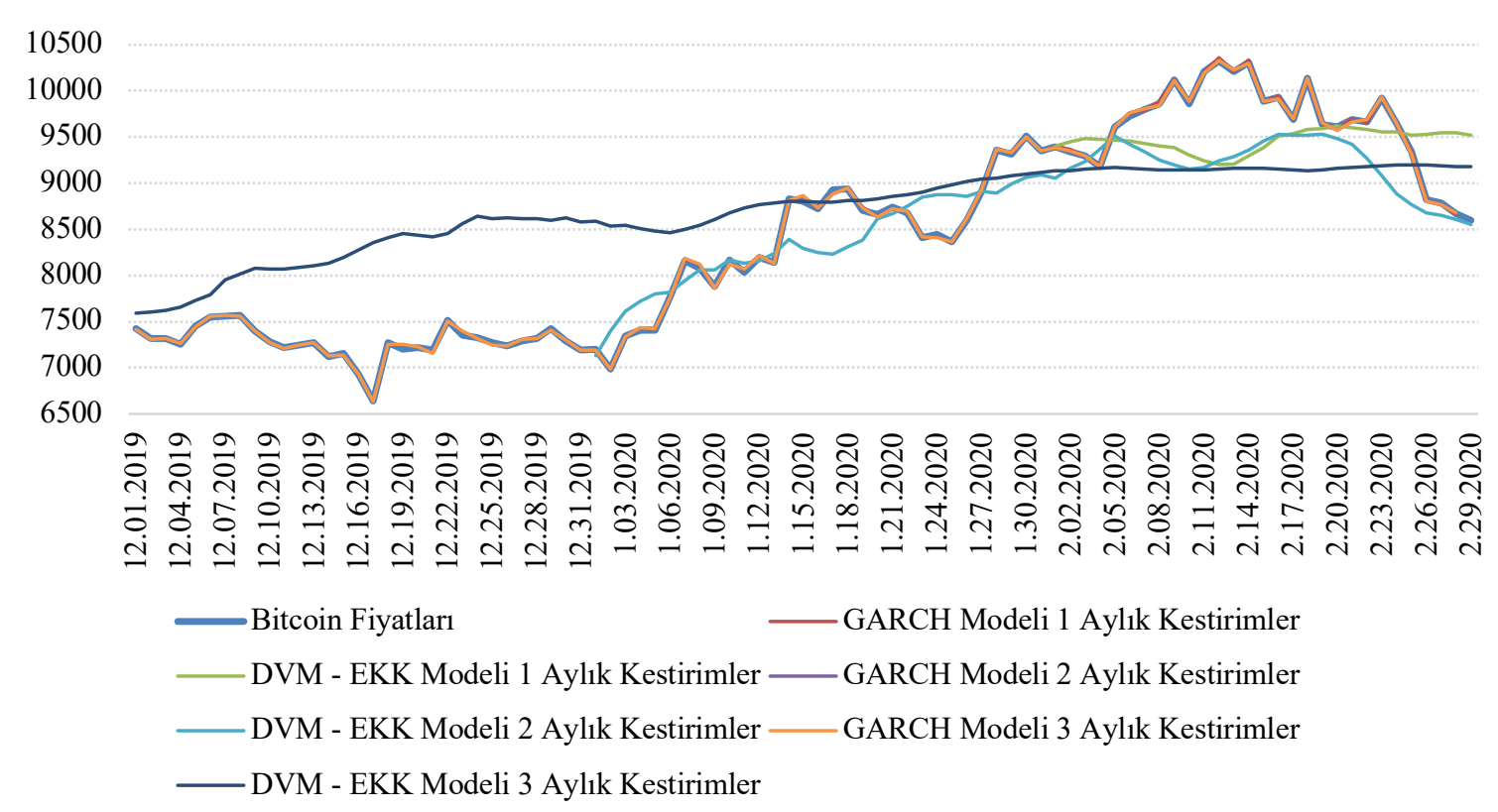

Şekil 3. Örneklem Dışı Kestirimler

Şekildeki grafikler modellerin kestirim performanslarının oldukça iyi olduğunu daha net bir şekilde ortaya koymaktadır. Özellikle GARCH modeline ait kestirimler için eğriler orijinal seriye ait eğri ile çakışmıştır. Elde edilen bulgular makine öğrenmesi yöntemlerinin esnekliğine rağmen uygun fonksiyonel kalıbın kullanılması ve varsayımların göz ardı edilmemesi durumunda GARCH modeli gibi klasik modellerin oldukça başarılı kestirimler elde edilmesini sağlayabileceğini göstermektedir. Benzer şekilde Munim, Shakil ve Alon (2019), Hatori (2020) ve Walther vd. (2019) de klasik zaman serisi yöntemleriyle başarılı sonuçlar elde edilebileceği sonucuna ulaşmışlardır.

\section{Sonuçlar ve Öneriler}

Bu çalışmada amaç Bitcoin gibi kripto paralar için başarılı öngörülerin farklı yöntemlerle elde edilip edilemeyeceğinin belirlenmesidir. Finansal piyasalara ait seriler spekülasyonlar gibi bazı dışsal nedenlerle dalgalanmalar içerebilmektedir. Ayrıca genellikle doğrusal olmayan değişimler içermektedir. $\mathrm{Bu}$ gibi özellikleri, finansal zaman serileri için öngörülerin elde edilmesinde başarısızlıklara yol açmaktadır. Bu çalışmanda klasik zaman serisi modellerinden GARCH modeli ve bir makine öğrenme yöntemi olan DVM - EKK yöntemi ile Bitcoin fiyat serisine ait kestirimler elde edilmiş, model performansları karşılaştırılmıştır. Çalışmada 01 Ocak 2017 - 29 Şubat 2020 dönemi, 1155 günlük Bitcoin fiyat serisi $\left(P_{t}\right)$ kullanılmıştır. Her iki modelde de Bitcoin fiyat serisi ve bu seriye ait oynaklıklar kullanılmış, dışsal değişkenler modellere dahil edilmemiştir. Literatürde Bitcoin gibi kripto paralarla ilgili yapılmış pek çok çalışma olmasına rağmen pek çok çalışma oynaklık öngörüsüne odaklanmıştır. Çoğu çalışmada fiyat serisinin öngörüne odaklanılmamıştır.

Literatürde yaygın görüş, güncel makine öğrenmesi ve derin öğrenme yöntemlerinin esnekliği, dağılım varsayımında bulunmaması ve doğrusal olmayan zaman serilerinin öngörülerinde başarılı sonuçlar verdiği şeklindedir. Bunun yanında pek çok çalışmada karşılaştırma amacıyla da olsa klasik zaman serisi modelleri kullanılmışıır. Yaygın görüş bu yöntemlerin öngörü başarısının düşük olduğu biçimindedir. Bu çalışmada GARCH modeli ve DVM - EKK yöntemiyle öngörüler elde edilerek karşılaştırılmıştır. $\mathrm{Bu}$ gibi modellerde amaç gelecek değerlerin öngörülmesi olduğundan örneklem dışı performansların karşılaştırılması daha doğru olacaktır. Bu nedenle model performansları örneklem dışı sonuçlara göre karşılaştırılmıştır. DVM - EKK yöntemi örneklem içi çok başarılı sonuçlar elde edilmesini sağlasa da GARCH modeli örneklem dışı performans açısından 
daha başarılıdır. DVM - EKK yönteminin örneklem içi başarısı aşırı öğrenmeye bağlanabilir. GARCH modeli gibi yöntemler pek çok varsayım barındırdığından ve model spesifikasyonlarının belirlenmesine ait belirgin kurallar içermediğinden bu modellerin kullanılması çetrefilli bir hal alabilmektedir. Makine öğrenmesi yöntemleri ise bu konuda daha esnektir. Çoğu çalışmada elde edilen bulgular değin öğrenme ve makine öğrenme algoritmalarının daha başarılı sonuçlar elde edilmesini sağladığı yönündedir. Fakat bu çalışmada elde edilen bulgulara göre GARCH modeli daha başarılı öngörü performansları sergilemektedir.

Bu çalışmada sadece Bitcoin fiyat serisine ait öngörüler GARCH ve DVM - EKK yöntemleri ve bu seriye ait gecikmeli değerler kullanılarak elde edilmiştir. İlerdeki çalışmada farklı kripto para fiyat serileri için öngörüler elde edilebilir. Bunun yanında farklı zaman serisi modelleri, makine öğrenmesi ve derin öğrenme algoritmaları kullanılabilir. Ayrıca kullanılan modellere gecikmeli değerler yanında bazı dışsal faktörler de eklenebilir.

\section{Kaynakça}

Aalborg, H. A., Molnár, P., de Vries, J. E. (2019). What can explain the price, volatility and trading volume of Bitcoin? Finance Research Letters, 29, 255-265. https://doi.org/10.1016/J.FRL.2018.08.010

Adcock, R., Gradojevic, N. (2019). Non-fundamental, non-parametric Bitcoin forecasting. Physica A: Statistical Mechanics and Its Applications, 531, 121-727. https://doi.org/10.1016/J.PHYSA.2019.121727

Aslan, F., Pençe, I., Çeşmeli, M. S., Kalkan, A. (2018). Bitcoin'in Türkiye Piyasasındaki Değerinin Yapay Zeka Teknikleri ile Tahmini. In 5th International Management Information Systems Conference. 59-62

Balcilar, M., Bouri, E., Gupta, R., Roubaud, D. (2017). Can volume predict Bitcoin returns and volatility? A quantiles-based approach. Economic Modelling, 64, 74-81. https://doi.org/10.1016/J.ECONMOD.2017.03.019

Balli, F., de Bruin, A., Chowdhury, M. I. H., Naeem, M. A. (2019). Connectedness of cryptocurrencies and prevailing uncertainties. Applied Economics Letters, 0(0), 1-7. https://doi.org/10.1080/13504851.2019.1678724

Bleher, J., Dimpfl, T. (2019). Today I got a million, tomorrow, I don't know: On the predictability of cryptocurrencies by means of Google search volume. International Review of Financial Analysis, 63, 147-159. https://doi.org/10.1016/J.IRFA.2019.03.003

Bollerslev, T. (1986). Generalized Autoregressive Conditional Heteroskedasticity. Journal of Econometrics, 31, 307-327. https://doi.org/10.1109/TNN.2007.902962

Ceylan, F., Tüzün, R., Ekinci, O., Kahyaoğlu, H. (2018). Kripto Para Piyasasında Balonların Tespiti: Bitcoin ve Ethereum Örneği. Business \& Management Studies: An Internatıonal Journal, 6(3), 263-274. https://doi.org/10.15295/bmij.v6i3.355

Çılgın, C., Ünal, C., Alıcı, S., Akkol, E., Gökşen, Y. (2020). Metin Sınıflandırmada Yapay Sinir Ağları ile Bitcoin Fiyatları ve Sosyal Medyadaki Beklentilerin Analizi. MAKÜ-Uyg. Bil. Derg, 4(1), 106-126. https://doi.org/10.31200/makuubd.651904

CoinMarketCap. (2020). https://coinmarketcap.com/

Cortes, C., Vapnik, V. (1995). Support-vector networks. Machine Learning, 20(3), 273-297. https://doi.org/10.1007/bf00994018 
da Silva Filho, A. C., Maganini, N. D., de Almeida, E. F. (2018). Multifractal analysis of Bitcoin market. Physica A: Statistical Mechanics and Its Applications, 512, 954-967. https://doi.org/10.1016/J.PHYSA.2018.08.076

Demir, A., Akılotu, B., Kadiroğlu, Z., Şengür, A. (2019). Makine Öğrenmesi Yöntemleri Kullanılarak Bitcoin Tahmini. 2019 1st International Informatics and Software Engineering Conference, 1-4.

Engle, R. F. (1982). Autoregressive Conditional Heteroscedasticity with Estimates of the Variance of United Kingdom Inflation. Econometrica, 50(4), 987-1007. https://doi.org/10.2307/1912773

Evci, S. (2020). Bitcoin Piyasasında Haftanın Günü Anomalisi. Alanya Akademik Bakış, 4(1), 5361. https://doi.org/10.29023/alanyaakademik.664776

Fan, G.-F., Peng, L.-L., Hong, W.-C., Sun, F. (2016). Electric load forecasting by the SVR model with differential empirical mode decomposition and auto regression. Neurocomputing, 173, 958-970. https://doi.org/10.1016/j.neucom.2015.08.051

Figá-Talamanca, G., Patacca, M. (2019). Does market attention affect Bitcoin returns and volatility? Decisions in Economics and Finance, 42(1), 135-155. https://doi.org/10.1007/s10203-01900258-7

Garman, M. B., Klass, M. J. (1980). On the Estimation of Security Price Volatilities from Historical Data. The Journal of Business, 53(1), 67-78. http://www.jstor.org/stable/2352358

Giudici, P., Pagnottoni, P. (2019). High Frequency Price Change Spillovers in Bitcoin Markets. RISKS, 7(4). https://doi.org/10.3390/risks7040111

Güleç, Ö. F., Çevik, E., Bahadır, N. (2018). Bitcoin ile Finansal Göstergeler Arasındaki İlişkinin İncelenmesi. Kırklareli Üniversitesi İktisadi ve İdari Bilimler Fakültesi Dergisi, 7(2), 18 37. https://doi.org/10.33707/akuiibfd.567902

Hattori, T. (2020). A forecast comparison of volatility models using realized volatility: evidence from the Bitcoin market. Applied Economics Letters, 27(7), 591-595. https://doi.org/10.1080/13504851.2019.1644421

Haykin, S. (1999). Neural networks: a comprehensive foundation (Second Edition ed.). Singapore: Prentice Hall PTR.

Isah, K. O., Raheem, I. D. (2019). The hidden predictive power of cryptocurrencies and QE: Evidence from US stock market. Physica A: Statistical Mechanics and Its Applications, 536, 121032. https://doi.org/10.1016/J.PHYSA.2019.04.268

Kanat, E., Öget, E. (2018). Bitcoin ile Türkiye ve G7 Ülke Borsaları Arasindaki Uzun ve Kısa Dönem İlişkilerin İncelenmesi. Finans Ekonomi ve Sosyal Araştırmalar Dergisi, 3(3), 601-614. https://doi.org/10.29106/fesa.422113

Karasu, S., Altan, A., Saraç, Z., Hacioğlu, R. (2018). Prediction of Bitcoin prices with machine learning methods using time series data. 2018 26th Signal Processing and Communications Applications Conference (SIU), 1-4. https://doi.org/10.1109/SIU.2018.8404760

Kartal, C. (2020). Bitcoin Fiyatlarinin K-Star Algoritmasi İle Modellenmesi. BMIJ, 8(1), 213-231. https://doi.org/10.15295/bmij.v8i1.1380

Karthika, S., Margaret, V., Balaraman, K. (2017, 21-22 April 2017). Hybrid short term load forecasting using ARIMA-SVM. Paper presented at the 2017 Innovations in Power and Advanced Computing Technologies (i-PACT). 
Kaytez, F. (2012). En Küçük Kareler Destek Vektör Makineleri ile Türkiye’nin Uzun Dönem Elektrik Tüketim Tahmini ve Modellemesi. Doktora Tezi, Gazi Üniversitesi.

Kaytez, F., Taplamacioglu, M. C., Cam, E., Hardalac, F. (2015). Forecasting electricity consumption: A comparison of regression analysis, neural networks and least squares support vector machines. International Journal of Electrical Power \& Energy Systems, 67, 431-438. https://doi.org/10.1016/j.ijepes.2014.12.036

Kristjanpoller, W., Minutolo, M. C. (2018). A hybrid volatility forecasting framework integrating GARCH, artificial neural network, technical analysis and principal components analysis. Expert Systems with Applications, 109, 1-11. https://doi.org/10.1016/J.ESWA.2018.05.011

Lahmiri, S., Bekiros, S. (2019). Cryptocurrency forecasting with deep learning chaotic neural networks. Chaos, Solitons \& Fractals, 118, 35-40. https://doi.org/10.1016/J.CHAOS.2018.11.014

Li, X., Wang, C. A. (2017). The technology and economic determinants of cryptocurrency exchange rates: The case of Bitcoin. Decision Support Systems, 95, 49-60. https://doi.org/10.1016/J.DSS.2016.12.001

Mallqui, D. C. A., Fernandes, R. A. S. (2019). Predicting the direction, maximum, minimum and closing prices of daily Bitcoin exchange rate using machine learning techniques. Applied Soft Computing Journal, 75, 596-606. https://doi.org/10.1016/j.asoc.2018.11.038

Munim, Z. H., Shakil, M. H., Alon, I. (2019). Next-Day Bitcoin Price Forecast. Journal of Risk and Financial Management, 12(2), 1 - 15. https://doi.org/10.3390/jrfm12020103

Nakamoto, S. (2008). Bitcoin: a peer-to-peer electronic cash system. https://bitcoin.org/bitcoin.pdf

Pele, D. T., Mazurencu-Marinescu-Pele, M. (2019). Using High-Frequency Entropy to Forecast Bitcoin's Daily Value at Risk. Entropy, 21(2). https://doi.org/10.3390/e21020102

Rane, P. V., Dhage, S. N. (2019). Systematic Erudition of Bitcoin Price Prediction using Machine Learning Techniques. 2019 5th International Conference on Advanced Computing \& Communication Systems (ICACCS) Systematic.

Şahin, E. E. (2018). Crypto Money Bitcoin: Price Estimation With ARIMA and Artificial Neural Networks. Fiscaoeconomia, 2(2), 74-92. https://doi.org/10.25295/fsecon.2018.02.005

Şahin, E. E., Özkan, O. (2018). Asimetrik Volatilitenin Tahmini : Kripto Para Bitcoin Estimation Of Asymmetric Volatility: Crypto Money Application. Bilecik Şeyh Edebali Üniversitesi Sosyal Bilimler Enstitüsü Dergisi, 3(2), 240-247.

Selgin, G. (2015). Synthetic commodity money. Journal of Financial Stability, 17, 92-99. https://doi.org/10.1016/J.JFS.2014.07.002

Sun, X., Liu, M., Sima, Z. (2020). A novel cryptocurrency price trend forecasting model based on LightGBM. Finance Research Letters, 32, 1 - 6. https://doi.org/10.1016/J.FRL.2018.12.032

Suykens, J. A. K., Vandewalle, J. (1999). Least Squares Support Vector Machine Classifiers. Neural Processing Letters, 9(3), 293-300. https://doi.org/10.1023/a:1018628609742

Troster, V., Tiwari, A. K., Shahbaz, M., Macedo, D. N. (2019). Bitcoin returns and risk: A general GARCH and GAS analysis. Finance Research Letters, 30, 187-193. https://doi.org/10.1016/J.FRL.2018.09.014

Walther, T., Klein, T., Bouri, E. (2019). Exogenous drivers of Bitcoin and Cryptocurrency volatility - A mixed data sampling approach to forecasting. Journal of International Financial Markets, Institutions and Money, 63, 101 - 133. https://doi.org/10.1016/j.intfin.2019.101133 
Wołk, K. (2019). Advanced social media sentiment analysis for short-term cryptocurrency price prediction. Expert Systems, e12493. https://doi.org/10.1111/exsy.12493

Xuemei, L., Jin-hu, L., Lixing, D., Gang, X., Jibin, L. (2009). Building Cooling Load Forecasting Model Based on LS-SVM. 55-58. Paper presented at the 2009 Asia-Pacific Conference on Information Processing, https://doi.org/10.1109/apcip.2009.22 